\section{TONY DUE AT THE PALACE}

Anthony (Tony) David Griffin has been appointed MBE in the Queen's Birthday Honours 2014 for services to dental technology.

Tony is Past President of the Dental Technologists Association (DTA) and Past Chairman of DTETAB (the Dental Technicians Education and Training Advisory Board); he is also Honorary Treasurer and an Elected Council member of DTA. Tony has dedicated his professional life to helping establish clinical dental technology and supporting dental technology and dental nursing within the healthcare provision of the dental team.

Tony worked for over 30 years in a variety of management roles starting at People’s College of Further Education,
Nottingham and with direct links to De Montfort University,

Leicester. More recently he has

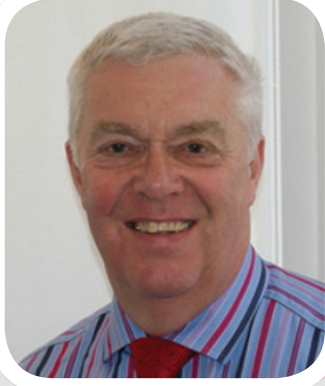
developed a

portfolio career that includes a national quality assurance role along with other paid and voluntary work.

DTA President Mike McGlynn said: 'This is terrific news for Tony and is well deserved recognition of his hard work and commitment to dental technology over many years. We are fortunate to be able to call upon Tony's wealth of experience here at DTA and are delighted that his services to our profession have been given a royal seal of approval!'

\section{PHOTO STORY}

Four dental nurses who appeared in the ITV's behind-the-scenes documentary 'The Dentists' filmed at Manchester's University Dental Hospital and broadcast on 16 June 2014. The nurses are, from left to right, Dawn Harrison, Lana Mellor, Jo Virgin and Sarah Hardman

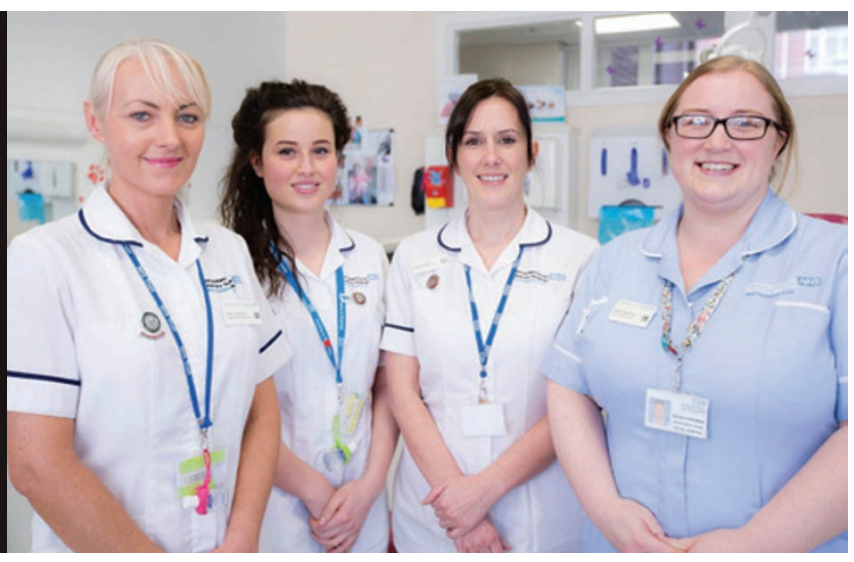

CALL TO ACTION ON CARIES IN CHILDREN

Following the broadcast of 'The Dentists', a behind-the-scenes documentary filmed by ITV at the University Dental Hospital of Manchester, the British Society of Paediatric Dentistry (BSPD) wants to make it easier for children with caries to get early access to a paediatric dentist.

BSPD representatives want to engage with the Department of Health and colleagues in the dental as well as health and social care professions in order to come up with a co-ordinated approach to tackling the issue of caries in children.

The Dentists showed the operations and procedures provided at the University Dental Hospital of Manchester, including two general anaesthetics on children undergoing multiple extractions and interviews with their parents.

Claire Stevens, a Consultant in Paediatric Dentistry at the University Dental Hospital of Manchester, and spokeswoman for BSPD, said: 'If these children had seen a paediatric dentist earlier, it might have been possible to save their teeth, instead of removing them and potentially triggering dental anxieties for life'

The BSPD is concerned because some Community Dental Services are cutting back on paediatric dentists. The society is grateful to ITV for highlighting the challenges hospital dental teams face as well as the work of specialist paediatric dentists and their teams. What the programme did not show was the follow-up preventive advice to parents to get those child patients on the road to dental health and visiting a dentist.

Dr Stevens said: 'It should be borne in mind that some children are inherently more susceptible to dental decay than others. A number of our patients end up in hospital because of a hereditary or medical condition and not because their parents are at fault.

\section{A PERFECT STORM OF POSSIBILITIES FOR HYGIENISTS}

The Journal of Evidence-Based Dental Practice (JEBDP) say that it is an exciting time in the profession of dental hygiene, with opportunities to take increased responsibility for oral health care and to deliver care in a more comprehensive way.

The US editors of JEBDP have presented the Annual Report on Dental Hygiene, a collection of cutting-edge research and practice updates in the field of dental hygiene.

In an introduction to the special issue, Guest Editor Dr Terri Tilliss RDH PhD of the University of Colorado School of Dental Medicine says: 'Societal, economic, political, and health care factors have converged to create a "perfect storm" of unprecedented possibilities for improved access to oral health care and growth for dental hygienists.'

The introduction goes on to say that dental hygienists are poised to assume a more independent and direct role in providing dental care - a key part of strategies to expand access to oral health and medical care to underserved areas and populations. The special issue of JEBDP presents 27 invited articles contributed by leading clinicians and researchers from dental hygiene, dentistry, and other disciplines.

It reports on dentistry's role in managing shared risk factors for periodontal and medical diseases; assembles evidence on periodontal treatment, care of implant-supported restorations, approaches to fluoride therapy, and oral health; provides updates on dental professionals' contributions to managing a wide range of medical conditions; reviews changing public needs and access to care; and highlights professional growth opportunities for dental hygienists.

Copies of the Annual Report on Dental Hygiene published by Elsevier can be ordered by visiting www.jebdp.com.
Do you have a news story that you would like included in BDJ Team? Send your press release or a summary of your story to the Editor at bdjteam@nature.com. 